\title{
Simple Arm Muscle Model for Oil Palm Harvesting Process
}

\author{
Aliff Rahman ${ }^{1}$, Shahrol Mohamaddan ${ }^{1, a}$, Noor Aliah Abdul Majid ${ }^{1}$, Magdalene Andrew-Munot ${ }^{1}$, Nur Tahirah Razali ${ }^{1}$, \\ Baba Md Deros ${ }^{2}$ and Syah Runniza Ahmad Bakri ${ }^{3}$ \\ ${ }^{1}$ Department of Mechanical and Manufacturing, Faculty of Engineering, Universiti Malaysia Sarawak (UNIMAS), 94300 Kota \\ Samarahan, Sarawak, Malaysia \\ ${ }^{2}$ Department of Mechanical and Materials Engineering, Faculty of Engineering, Universiti Kebangsaan Malaysia, 43600 UKM Bangi, \\ Selangor, Malaysia \\ ${ }^{3}$ Faculty of Computer Science and Mathematics, Universiti Teknologi MARA, 94300 Kota Samarahan, Sarawak, Malaysia
}

\begin{abstract}
Arm are essential in order to perform manual material handling work that normally involves lifting, handling, placing, push and pull, carrying and moving heavy loads. When these work elements are performed over prolonged periods repeatedly, it will expose workers arm to awkward posture and possible ergonomic risk factor. For example, work element that requires repetitions frequently may lead the arm to face physical stress and mental fatigue. The situation can be extremely risky if the worker task requires higher focus or time consumable. These issues are unavoidable in palm oil harvesting process since the workers are still using manual handling when harvesting the fresh fruit bunch (FFB). The worker using a chisel to harvest the young palms and a sickle mounted on a bamboo or aluminum pole to harvest taller palms. When perform this work element combining with heavy physical workload, it may lead to work-related muscle disorders (WSMDs). This study was conducted to identify the force reaction and inverse dynamic analysis during oil palm harvesting process using ergonomics software called Anybody Technology. Inverse dynamic analysis is a technique for figuring strengths and/or moments of power (torques) taking into account the kinematics (movement) of a body and the body's inertial properties.
\end{abstract}

\section{Introduction}

Arm are essential in order to perform manual material handling work that normally involves lifting, handling, placing, push and pull, carrying and moving heavy loads [1]. Tasks that require forceful exertions place higher loads on the muscles, tendons and joints of arm. Increasing the force means increasing the body demands such as higher muscle exertion. The weight and height of a load that has to be lifted and the frequency of lifting are the factors that will contribute to the level of exertion on the muscles and joints of the arm.

In addition, when these work elements are performed over prolonged periods and repeatedly, it will expose the arm to awkward posture and possible ergonomics risk factor. For example, work element that requires repetitions frequently may cause physical stress on the arm and also mental fatigue. This situation can be extremely risky if the worker task requires higher focus and time consumable.

This issues are unavoidable in palm oil harvesting process due to the workers are still using manual handling when they harvest the fresh fruit bunch (FFB)[2]. In spite of the fact that there have been a few improvements and interventions have been done on the harvesting tools, the estate are still utilizing the manual tools and depending on the labor strength. The worker is still using a chisel to harvest the palms that are reachable and a sickle that is mounted to or aluminum pole to harvest taller palms.

This work element is causing heavy physical workload to the workers and it may lead to work-related muscle disorders (WSMDs). This may contribute to awkward posture that leads to fatigue discomfort and injury. There are some assessment that has been done to investigate the posture and possible risk of the worker when using the palm oil harvesting tools. Rapid Entire Body Assessment REBA [3], Rapid Upper Limb Analysis RULA [4] and Quick Exposure Check QEC [5] are some of the techniques used to determine the possible musculoskeletal risk.

REBA techniques are used to investigate the possible risk of the entire body sections for example trunk, wrists, arms and legs. It is a worksheet of survey for whole body movement based on the task of palm oil harvesting process [6]. RULA technique is focusing on the posture of worker.

RULA analysis focuses on time cycle, number of movements, static muscle force and the working posture. These factors will be analyses and resulted in the form of score with the range of 1-7. QEC is a technique used to determine the possible of musculoskeletal disorder. It focuses on four main section of human body which is back bone, shoulder/hand, wrist/arm and neck. This technique also include the psychosocial factor evaluation, the movement and it frequency.

The objective of this paper is focusing on identifying the length of contraction of arm muscle and the reaction force throughout the movement of arm through Inverse Dynamic Analysis. It is a technique for figuring strengths and/or moments of power (torques) taking into account the kinematics (movement) of a body and the body's inertial properties (mass and moment of inactivity).

In this research, the AnyBody Modelling System programming is utilized. AnyBody is an intense devices that immeasurably utilized by examination foundations to recreate the musculoskeletal. It empowers analysts and understudies to assemble and investigate musculoskeletal model, or to make adjustments of existing models.

\footnotetext{
a Corresponding author: mshahrol@unimas.my
} 
AnyBody programming is utilized for breaking down the responses inside of the human body or the cooperation of human body with a favoured situation.

The framework permits client to show and dissect any musculoskeletal framework either human or creature [7]. The framework are accompanied with full body demonstrate that can be adjustable as per clients inclinations and necessities. Body movements and external force can be adjusted in the AnyBody programming to ascertain the individual muscle reaction to certain development.

\section{Methodology}

\subsection{Modeling Harvesting Tools}

This study starts with modelling the tools for oil palm harvesting process using $3 \mathrm{D}$ design software. There are three main tools that have been applied in the harvesting process namely the chisel, pole and loading spike as shown in Figure 1. In the 3D design, the dimensions of the tools had followed the current/existing specification.
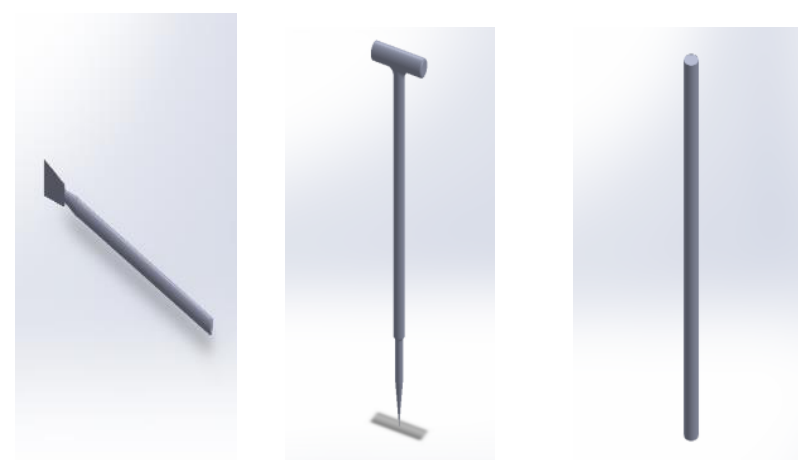

Chisel Loading Spike Aluminium Pole Figure 1. Modelled harvesting tools using 3D modelling software

Chisel is used to cut the fresh fruit bunch (FFB). This is applicable for the small size tree. Pole is used to cut the FFB with long-armed sickle. This is aimed for high size tree. Lastly, the loading spike is used to stomp the FFB and lift it on the shoulder.

\subsection{Modeling Simple Arm Muscle Model}

Simple Arm Muscle was modeled using Anybody Technology Software. AnyScript Programming was used to design the segment of arm, muscle and the movement. The data had been input manually into the programming command. Two segments of arm namely the upper arm and forearm were formed. Upper arm is the extended segment from the shoulder to the elbow. The segment focused on lifting and pulling strength. Forearm is the segment from the elbow to the risk and focused on the wrist extension, flexion and rotation.
Elbow acts as the hinged between the upper arm and forearm. It allows the segment to rotate until 180 degrees; the normal arm full extension. The segments then are linked with the muscle. There are 4 muscles that linked the segment which is deltoid, triceps, biceps and brachialis. Figure 2 shows the simple arm muscle model based on actual anatomy of the arm [8].

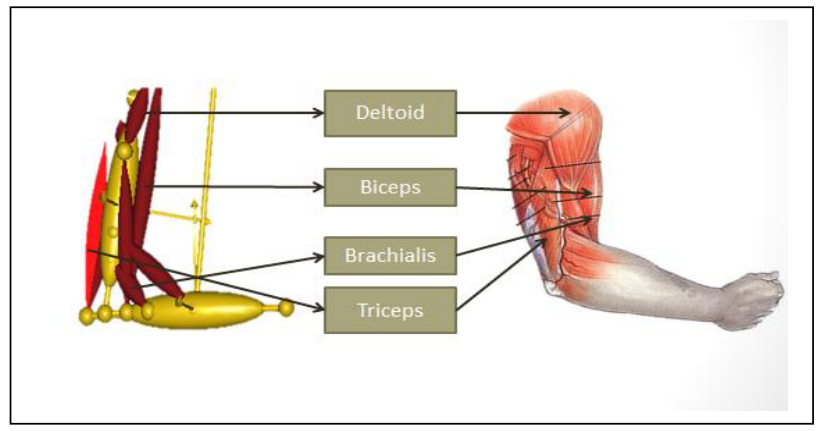

Figure 2. Simple arm muscle vs actual anatomy [8]

\subsection{Modelling Simple Arm Muscle Model Using Harvesting Tools}

The simple arm muscle model was then remodelled by adding a harvesting tool in the environment condition. The angle of posture and movement of arm during the work element had been input into the AnyScript programming manually according to the working condition. Table 1 show the model of simple arm using harvesting tools.

\subsection{Data Analysis - Inverse Dynamics}

Inverse dynamics analysis was depends on the stimulated muscle and joint strengths of the whole body that experience specific complex movements. It also took dynamic inertia forces into consideration and was not necessarily requiring the measured forces in the interface which was between the body and the environment. Inverse dynamic analysis had the advantages which it includes the consideration in investigation of extremely complex musculoskeletal frameworks that may including with several of muscles.

In this research, the focus was on using the inverse dynamic analysis to determine the reaction force of the muscle and the length of contraction. In order to understand and investigate the better posture during the harvesting process, it is crucial to determine how the muscle reacts through the movement of task.

In palm oil harvesting process the task such as pulling, pushing and lifting was required to be performed by the workers. The task involved a lot of forces and energy. Besides the forces or energy performed by the body, there is a need to consider others parameters such as the weight of the fresh fruit bunch (FFB) and the harvesting tools. In the simulation conducted, the unit for force was in Newton $(\mathrm{N})$ while length was in meter (m). 
Table 1. Simple arm muscle model using harvesting tools
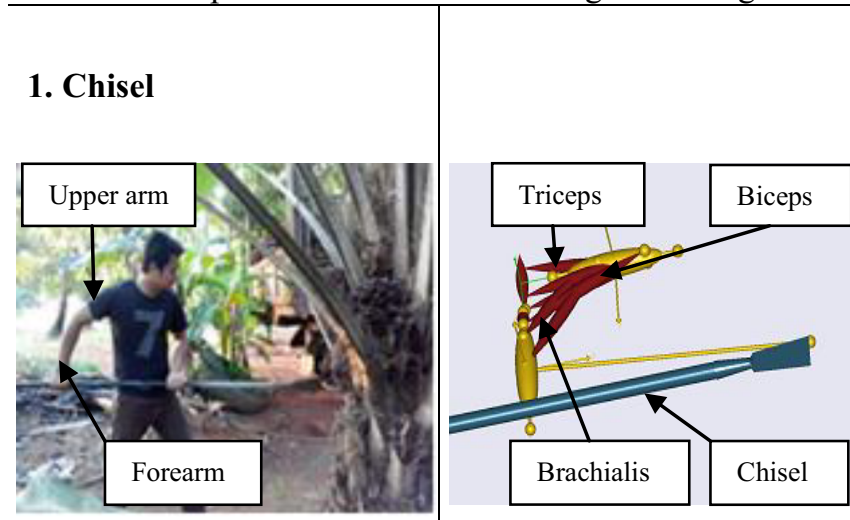

2. Pole
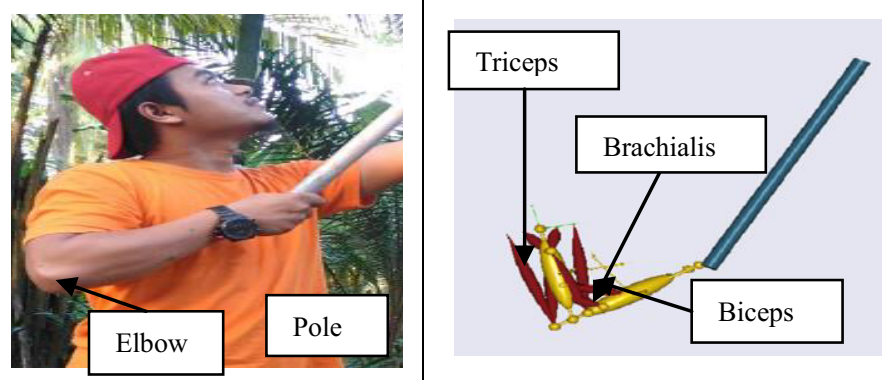

\section{Loading Spike}
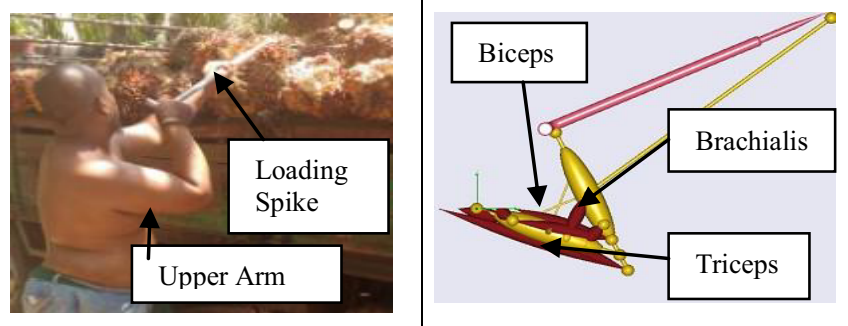

\section{Results and Discussion}

The analysis was performed to the simple arm muscle model based on the selected muscle. The analysis discussed the reaction forces exerted to the muscle and the contraction length of the muscle when using different harvesting tools. There were three selected muscles including Biceps, Triceps and Brachialis. Biceps is a 2headed muscle that link to the upper arm between the elbow and shoulder. Triceps is the largest muscle in the upper limb. The muscle is responsible for the extension of elbow joint when straightening the arm. Lastly, Brachialis is a muscle at the upper arm that flexes elbow joint.

Figure 3 and 4 show the contraction force and length of the Biceps muscle corresponding to time based on the three harvesting tools. For pole, it shows that at 0.00 second the reaction force is $3.50 \mathrm{E}+02 \mathrm{~N}$ and contraction length is $3.89 \mathrm{E}-01 \mathrm{~m}$. The value shows that in order to lift the aluminium pole, biceps muscle required $3.50 \mathrm{E}+02 \mathrm{~N}$ as the arm start to move vertically. At this point the arm is bending upwards at 75 degrees.

For chisel, it shows that at 0.00 second the initial force is $2.91 \mathrm{E}-01 \mathrm{~N}$ and the contraction length is $2.92 \mathrm{E}$ $01 \mathrm{~m}$. The value shows that in order to start moving horizontally, biceps muscle required $2.91 \mathrm{E}-01 \mathrm{~N}$ to move the chisel. At this point the arm is bending horizontally at 25 degrees. For loading spike, it shows that at 0.00 second the initial force is $4.02 \mathrm{E}+03 \mathrm{~N}$ and contraction length is $4.68 \mathrm{E}-01 \mathrm{~m}$. The value shows that in order to start lifting the loading spike vertically, biceps muscle required $4.02 \mathrm{E}+03 \mathrm{~N}$ to move upward. At this point the arm is bending downwards at 150 degrees.

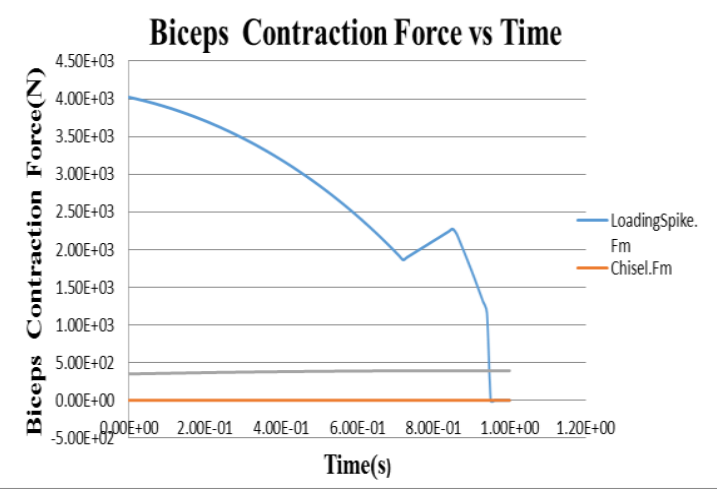

Figure 3. Contraction force of Biceps muscle

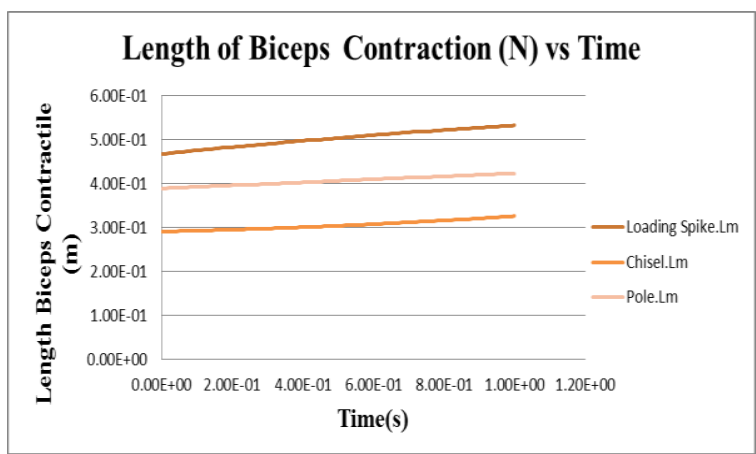

Figure 4. Contraction length of Biceps muscle

Figure 5 and 6 show the contraction force and length of the Triceps muscle corresponding to time based on three harvesting tools. For pole, it shows that at 2.00E01 second the reaction force is $2.18 \mathrm{E}-04 \mathrm{~N}$ and contraction length is $4.83 \mathrm{E}-01 \mathrm{~m}$. The value showed that in order to lift the aluminium pole, Triceps muscle required $2.18 \mathrm{E}-04 \mathrm{~N}$ as the arm start to move vertically. At this point the arm is bending upwards at 135 degrees.

For chisel, it shows that at $2.00 \mathrm{E}-01$ second the initial force is $2.51 \mathrm{E}+03 \mathrm{~N}$ and the contraction length is $2.92 \mathrm{E}-01 \mathrm{~m}$. The value shows that in order to start moving horizontally, Triceps muscle required $2.51 \mathrm{E}+03$ $\mathrm{N}$ to move the chisel. At this point the arm is bending horizontally at 55 degrees. For loading spike, it shows that at $2.00 \mathrm{E}-01$ second the initial force is $2.15 \mathrm{E}-07 \mathrm{~N}$ and contraction length is $3.96 \mathrm{E}-01 \mathrm{~m}$. The value shows that in order to start lifting the loading spike vertically, 
triceps muscle $2.15 \mathrm{E}-07 \mathrm{~N}$ to move upward. At this point the arm is bending downwards at 110 degrees.

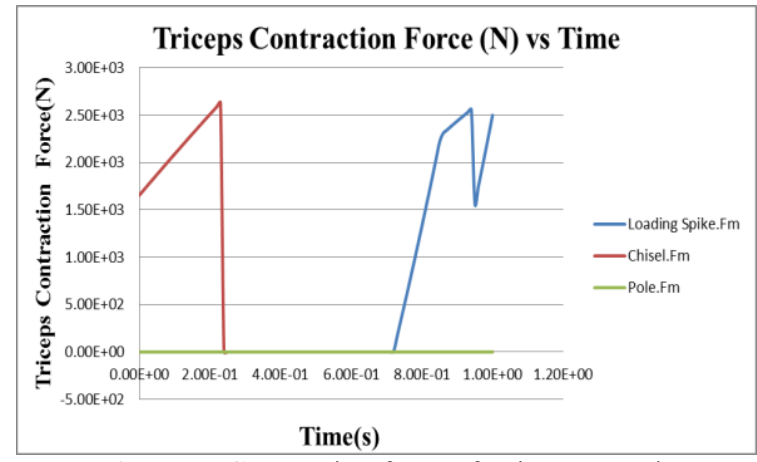

Figure 5. Contraction force of Triceps muscle

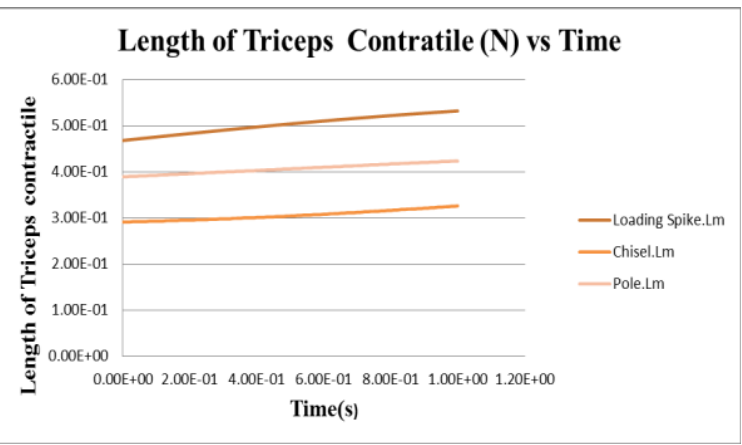

Figure 6. Muscle contraction length of the Triceps muscle

Figure 7 and 8 shows the contraction force and contraction length of the Brachialis muscle corresponding to time based on the three harvesting techniques. For pole, it shows that at $8.50 \mathrm{E}-01$ second the reaction force is $8.14 \mathrm{E}-07 \mathrm{~N}$ and contraction length is $5.24 \mathrm{E}-01 \mathrm{~m}$. The value shows that in order to lift the aluminium pole, Brachialis muscle required $8.14 \mathrm{E}-07 \mathrm{~N}$ as the arm start to move vertically.

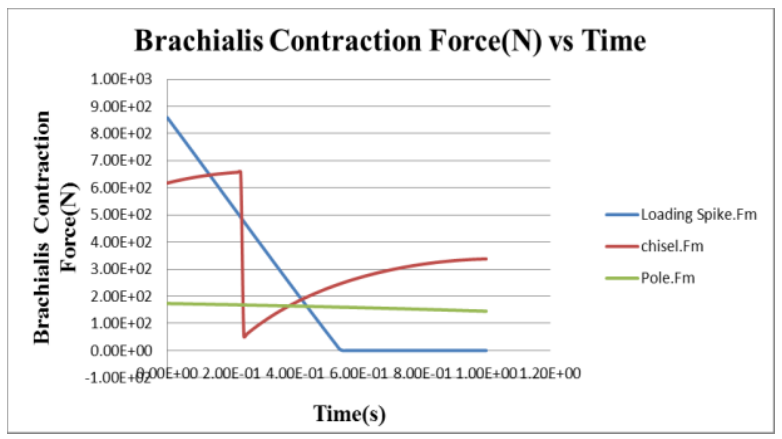

Figure 7 Contraction force of Brachialis muscle

At this point the arm is bending upwards at 160 degrees. For chisel, it shows that at $2.00 \mathrm{E}-01$ second the initial force is $3.26 \mathrm{E}+02 \mathrm{~N}$ and the contraction length is $3.19 \mathrm{E}-01 \mathrm{~m}$. The value shows that in order to start moving horizontally, Brachialis muscle requires $3.26 \mathrm{E}+02 \mathrm{~N}$ to move the chisel. At this point the arm is bending horizontally at 95 degrees. For loading spike, it shows that at $2.00 \mathrm{E}-01$ second the initial force is $1.50 \mathrm{E}+02 \mathrm{~N}$ and contraction length is $4.18 \mathrm{E}-01 \mathrm{~m}$. The value shows that in order to start lifting the loading spike vertically, Brachialis muscle required $1.50 \mathrm{E}+02 \mathrm{~N}$ to move upward.
At this point the arm is bending downwards at 85 degrees.

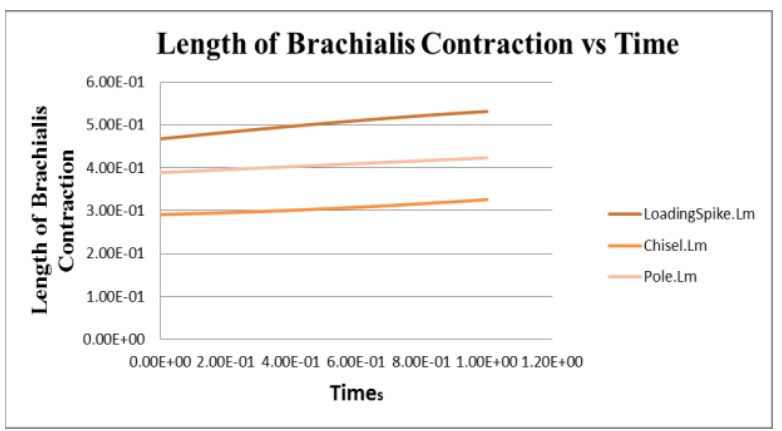

Figure 8. Muscle contraction length of the Brachialis muscle

\section{Conclusions}

Simple arm muscle model is the simplified stage of investigation to measure reaction exerted to the human arm when performing the harvesting process by using different tools. These work elements should be analysed further in order to assist reducing the potential injury due to work-related muscle disorders. The musculoskeletal of human are mechanically complex and needs a lot of interconnected tasks and consideration.

\section{Acknowledgement}

This research is funded by UNIMAS MyRA Special Grant Schemes [Grant no: F02/SpSTG/1385/16/27]. The authors would like to thank Universiti Malaysia Sarawak (UNIMAS) for providing facilities for this research.

\section{References}

1. Deros, B. M., Daruis, D. D. I., \& Basir, I. M. A. S. Ergo A. M.M.H, 195, 1666-1673(2015)

2. Nawi, N. S. M., Deros, B. M., \& Norani, N. J. Oil Palm Res. 10, pp. 122-127( 2013)

3. Hignett, S, \& McAtamney, L. R.E.B.A Ergo, 31, 201-5. (2000)

4. Deros, B. M., Khamis, N. K., Mohamad, D., Kabilmiharbi, N, \& Daruis, D. D. I. I. Oil Palm R.U.L.A. 287-290. (2014)

5. G. Li, P. Buckle, A.P Wok. Mus. Q.E.C. $1351-1355$, (1998)

6. Nawi, N. S. M., Deros, B. M., \& Norani, N. A. Oil Palm FFB. R.E.B.A, 10, 122-127, (2013).

7. M.Damsgaard, J. Rasmussen, Anal. Mus. Syst. Any. Mod.System,(2006)

8. Moore, K. L., Dalley, A. F, A. M. Cli. O. Ana. (2013) 